\title{
MIGRAÇÕES CONTEMPORÂNEAS: REPRESENTAÇÕES E SENTIDOS DO DESENVOLVIMENTO E DA COOPERAÇÃO
}

\author{
Luiz Carlos de Oliveira Borges ${ }^{1}$
}

\section{RESUMO}

O artigo trata da análise das complexas interfaces das migrações internacionais contemporâneas: o deslocamento forçado de um grande contingente de populações provenientes da Ásia e da África com destino aos países industrializados da Europa. Se servindo de um referencial teórico da epistemologia do Sul, o fenômeno é examinado em seus aspectos antropológicos e culturais. Através de uma metodologia multidisciplinar resultada da combinação de dois suportes de textos distintos - o escrito e o audiovisual - é estabelecido o cotejamento de conceitos da palavra e significados das imagens. Do primeiro são examinadas as categorias do Desenvolvimento e da Cooperação, da sua perspectiva ocidental, prescritiva, hierárquica e binária. Sua relação e contingências com a realidade social dos imigrantes. Tanto em sua forma objetiva como na construção de subjetividades. Do segundo tipo de texto, a reflexão problematiza uma leitura das imagens de representação das realidades sociais dos pontos de partidas e destino destes imigrantes (Sri Lanka e França) impressas no longametragem de ficção francês Deephan (2015), do diretor Jacques Audiard, vencedor da Palma de Ouro do Festival de Cannes neste mesmo ano.

Palavras-chave: Migrações. Desenvolvimento. Cooperação.

\begin{abstract}
The article deals with the analysis of complex interfaces of contemporary international migration: the forced displacement of a large number of people from Asia and Africa bound for industrialized countries in Europe. If serving a theoretical framework of epistemology of the South, the phenomenon is examined in its anthropological and cultural aspects. Through a multidisciplinary approach resulted from the combination of two supports of different texts - written and audiovisual - is established concepts of the comparison word and the meanings of the images. The first examines the categories of Development and Cooperation, a Western perspective, prescriptive, hierarchical and binary. Their relationship and contingencies with the social reality of immigrants. Both in its objective way in the construction of subjectivities. The second type of text, reflection discusses a reading of the social realities of representation images of matches and destination points of these immigrants (Sri Lanka and France) printed on the feature-length fiction "Deephan" (France, 2015), director Jacques Audiard, winner of the Cannes Film Festival's Palme d'Or the same year.
\end{abstract}

Keywords: Migration. Development. Cooperation.

\footnotetext{
${ }^{1}$ Doutorando do Programa de Pós-Graduação em Desenvolvimento, Sociedade e Cooperação Internacional da Universidade Brasília.
} 


\section{SEMINÁRIO DE PESQUISA EM CIÊNCIAS HUMANAS - SEPECH \\ Humanidades, Estado e desafios didático-científicos \\ Londrina, 27 a 29 de julho de 2016}

A migração é um fenômeno presente na história dos povos e grupos sociais em escala e proporção diversas. Na atualidade, a partir do deslocamento forçado de um grande contingente de populações provenientes da Ásia e da África com destino aos países industrializados da Europa, tal fenômeno parece assustar aqueles governos e sociedades como se fosse algo inédito ou ameaçador.

Segundo dados da Organização Internacional para as Migrações (OIM), da Organização das Nações Unidas (ONU), cerca de 1 (um) milhão de imigrantes adentraram no continente europeu somente em 2015. Realizada em condições informais e precárias, tal jornada tem produzido resultados trágicos: a morte de milhares de pessoas em sua travessia marítima; esta, quando exitosa, se depara com soerguimento das pontiagudas cercas dos Estados Nacionais da União Europeia (UE). Paradoxalmente, há pouco tempo, estas mesmas fronteiras foram destruídas para a circulação das mercadorias da globalização.

Os imigrantes são tratados como refugiados e indesejáveis sob a ótica da segurança e a estereotipia segregacionista; uma verdadeira ameaça à segurança e ao trabalho dos países da UE. O fenômeno expõe, entre outras coisas, o despreparo das arcaicas legislações migratórias dos países de destino e a ausência de memória e solidariedade de algumas nações. No passado, por razões semelhantes, guardadas as devidas proporções, um grande contingente de europeus emigrou para diversos continentes. Alguns foram acolhidos por outros governos, povos e outras culturas. Incorporados ao desenvolvimento, prosperaram e asseguram a continuidade de suas gerações.

Os motivos desta marcha contemporânea são inúmeros e combinados. Fogem da violência das guerras instauradas em seus países, da fome, das mudanças climáticas ou mesmo da escassez de oportunidades. Em qualquer uma das referidas situações, colocam em cheque modelos de desenvolvimento inadequados e reivindicam novas formas de cooperação.

Nas linhas que se seguem, as questões supramencionadas serão tratadas a partir de um diálogo que se percebe como possível entre um texto audiovisual contemporâneo que, sem dúvida, contribui para a apreciação do fenômeno (presente) das migrações internacionais tanto em seu plano simbólico quanto conceitual. Faz-se, portanto, a referência à película francesa Deephan (2015), do diretor Jacques Audiard - um longametragem de ficção, vencedor da Palma de Ouro do Festival de Cannes 2015. Vale destacar que o tema das migrações contemporâneas tem, de modo crescente, tomado a pauta de diversas cinematografias, o que, de certa forma, indica a crescente importância do tema nesta etapa de globalização. $O$ filme escolhido não se apresenta aqui apenas pelo seu norte temático, mas também porque suscita e inspira a discussão dos sentidos e das representações das realidades dos imigrantes com algumas noções conceituais sobre as categorias de desenvolvimento e a cooperação.

Deephan (2015) narra à trajetória de 03 (três) personagens que não se conhecem, até que se encontram no ato de emigração do Sri Lanka para a Europa. Deephan (JesuthasanAntonythasan), cujo nome confere o título original à obra, é um combatente do grupo étnico separatista Tamêis, que reivindica uma parte do território daquele país, com base na unidade linguística. $\mathrm{O}$ confronto de origem milenar com o povo Cingalês foi acentuado a partir do inicio dos anos 1980, quando a língua deste grupo foi instituída como oficial do país. Yaline (KalieaswariSrinivasan) é uma garota de semelhante procedência que, aterrorizada pela guerra, decide fugir para encontrar seus parentes que 


\section{SEMINÁRIO DE PESQUISA EM CIÊNCIAS HUMANAS - SEPECH \\ Humanidades, Estado e desafios didático-científicos \\ Londrina, 27 a 29 de julho de 2016}

se refugiaram na Inglaterra. Ilayaal (Claudine Vinasitamby) é uma criança abandonada, órfã da guerra civil que se abateu sobre o Sri Lanka. Após um bombardeio aéreo em um povoado daquele país, os personagens se encontram forçadamente no ato de imigração. O sucesso da fuga, ou seja, a entrada em outro país estando todos devidamente documentados, obrigam aos personagens a fazer uso de um disfarce como membros de uma mesma família: pai, esposa e filha. Tal vínculo é uma imposição decorrente da documentação arranjada: os passaportes. Neste ponto, o filme realiza uma elipse inserindo os personagens em uma nova realidade do destino possível: a França, sem apresentar a jornada migratória, certamente árdua e perigosa. Chama a atenção o fato de que, para garantir o acolhimento em seu destino, o porte dos documentos não basta. É preciso inventar e contar uma história convincente que o justifique, mesmo que não seja original, e repetida por vários imigrantes.

No território francês, os personagens são conduzidos pela ajuda humanitária a um conjunto habitacional de arquitetura vertical, situado na periferia de Paris - local também de destino de imigrantes de outras procedências, inclusive, de países da própria UE. Eles experimentam uma longa peregrinação no conhecimento, na adaptação e na sobrevivência na nova realidade. Neste sentido, muito contribui para o realismo da história o fato dos atores serem procedentes daquele país e a fala de seus personagens ser articulada na língua de origem, e não o francês. Através de nuances ora explícitas, ora sutis do encontro de culturas aparentemente antípodas (oriente-ocidente), o filme se desenvolve onde a necessidade da invenção da família para a sobrevivência em situações extremas assume seu eixo principal, apresentando, assim, uma abordagem instigante sobre o fenômeno contemporâneo da migração.

O primeiro tópico de aproximação que é possível estabelecer entre o texto audiovisual e as mencionadas noções conceituais sobre o desenvolvimento e a cooperação diz respeito à representação das realidades sociais dos pontos de partida e destino dos refugiados: as imagens do país pobre - Sri Lanka e do país rico - França, senão as imagens mesmo do conjunto dos países ricos industrializados da UE.

Deephan problematiza e expõe as dificuldades e limites dos referidos conceitos na perspectiva binária riqueza-pobreza que estiveram presentes nos primórdios das teorias de desenvolvimento e cooperação em sua epistemologia ocidental - conceitos que estabeleceram divisões entre os povos (desenvolvidos, subdesenvolvidos) e fundaram hierarquias, tendo por instrumento a régua do crescimento econômico e do progresso. Na visão de Ribeiro (2008), tal pensamento, em sua cosmogonia religiosa, ao adorar a si própria, ocultou as relações assimétricas de poder.

As imagens da pobreza do Sri Lanka e da riqueza da França, no filme, não são tão distinguíveis e opostas como se estabelece na mencionada epistemologia. Nestes termos, a substância material e imaterial das realidades em questão é tratada no filme em suas formas ambíguas, tênues, e por que não dizer complementares, tornando-se quase imperceptíveis, sem as fronteiras que as separam.

A fim de prosseguir com a análise das representações no filme é possível inserir algumas informações de caráter histórico e relevante para ampliar a compreensão e crítica dos conceitos de desenvolvimento e da cooperação, em sua origem eurocêntrica. Sem estas, o tratamento de tais termos pode ficar demasiadamente naturalizado. Segundo Gusovic (2000), o caráter de inevitabilidade, como um pensamento hegemônico do mundo globalizado, não permite outra abordagem destes conceitos como se propõe, por exemplo, a epistemologia do Sul. 


\section{SEMINÁRIO DE PESQUISA EM CIÊNCIAS HUMANAS - SEPECH \\ Humanidades, Estado e desafios didático-científicos \\ Londrina, 27 a 29 de julho de 2016}

O Sri Lanka é um país que foi descolonizado recentemente nos anos 1940. Desde 1983 encontra-se imerso em uma violenta guerra civil de disputa de identidades étnicas e que já matou mais de 70 mil pessoas. O conflito milenar entre os Cingaleses, os nativos de formação budista, e os Tâmeis, foi acirrado quando da independência se instituiu o Cingalês como língua oficial do país. Na visão de Tambiah (1976), os conflitos supramencionados remetem a questões do nacionalismo linguístico que, em suas disputas, justificam e tornam rotineiras e ritualistas as práticas de violência em nome de um ideário e herança sócio cultural que insistem em invocar fronteiras e lealdades exclusivistas, além de englobar as minorias, inferiorizando-as.

As imagens do Sri Lanka apresentadas brevemente no início do filme, quando se dá o mencionado ataque aéreo, apesar dos planos curtos e montagem frenética, na visão do desenvolvimento em sua perspectiva ocidental, trata-se de um povoado ou país populoso e pobre; porém, diante das condições de aparente miserabilidade, o sofrimento e o desespero humano causado pelo ataque impossibilita qualquer tentativa de avaliação ou classificação da representação daquela realidade a partir dos indicadores sociais desenvolvidos nos últimos 50 anos pelas mencionadas teorias do Produto Interno Bruto (PIB), entre outras. Além de se revelarem inadequadas, expõe sua base de subjetividade calcada na alteridade, tornando-se, portanto, insensível para examinar a realidades dos países hierarquizados pelo estigma do 'Terceiro Mundo'. Segundo Crespo e Gurovitz (2002), somente a partir dos anos 1990 é que se tem uma abordagem multidimensional, uma epistemologia do Sul para o desenvolvimento e a cooperação, que tornam possíveis outras mediações da realidade social daqueles países. Assim, é possível indagar se a pobreza ali presente é fruto da guerra ou se advém de situações anteriores, como, por exemplo, de um passado colonial do país e de sua emancipação recente da Inglaterra. Ou ainda, na perspectiva de Gudinaz (apud LANGE; MOKRANI, 2011), se decorrente do seu modelo de desenvolvimento centrado no extrativismo, produtor de desigualdades sociais, de alto custo e de grande impacto para a natureza.

Sabe-se que por décadas, o Sri Lanka viveu economicamente em torno da exploração do chá e da borracha. Em Deephan, as imagens da pobreza, apresentada de modo fugaz, se contrastam à riqueza da biodiversidade da região, onde as folhas de exuberantes palmeiras incineram os corpos abatidos no ataque bélico. No conflito riqueza-pobreza, onde prevalecem variáveis subjetivas, mais uma vez se revelam as ambiguidades e a contradição do pensamento desenvolvimentista predominantemente econômico. Neste sentido, segundo Pino e Dolcetti (2014), as promessas do progresso anunciadas pelas teorias ocidentais de desenvolvimento não chegaram àquela região, bem como em outras do planeta.

Retomando a análise do filme, as imagens de representação do destino dos refugiados - a França rica e industrializada, dos bulevares iluminados e do flanar intermitente das pessoas - é abruptamente substituída pela sua versão antípoda. A morada dos imigrantes é um conjunto habitacional, abandonado e depredado, situado na periferia de Paris, à margem do desenvolvimento. Uma zona de exclusão, um gueto; local também de destino de demais imigrantes, inclusive procedentes de países da própria UE. Com instalações precárias e sem a presença do Estado - que poderia promover o mínimo de bem estar social -, a área é um território livre ocupado por gangues urbanas que disputam o controle do território para o comércio e exploração ilegais: tráfico de armas, de drogas e de pessoas. Ali, a única presença do Estado se dá através dos serviços educacionais prestados por uma escola próxima ao condomínio, 


\section{SEMINÁRIO DE PESQUISA EM CIÊNCIAS HUMANAS - SEPECH \\ Humanidades, Estado e desafios didático-científicos \\ Londrina, 27 a 29 de julho de 2016}

onde os imigrantes são introduzidos à língua francesa. A manutenção deste serviço talvez permaneça vigente, uma vez que, segundo Ribeiro (2008), o desenvolvimento, enquanto um construto social, um discurso, requer o domínio de um léxico, uma fala.

A competência linguística, portanto, se apresenta com uma condição indispensável para os imigrantes ascenderem ao mercado de trabalho regular. Sair da sobrevivência informal das ruas, do comércio de bugigangas, possivelmente made in China. Dotado de um domínio rudimentar da nova língua - o francês - Deephan tornase o zelador do condomínio, e Yaline, empregada doméstica e cuidadora de um idoso. Para espanto e euforia destes personagens, a renda obtida por aqueles serviços, ainda que reduzida pela intermediação dos agentes, é maior comparativamente à que poderia ser obtida no Sri Lanka. Agora podem sair de sua morada monástica com o conforto dos objetos da indústria e, aos poucos, ir adquirindo uma razoável sociabilidade na comunidade de imigrantes. Porém, o estopim dos tiros entre gangues e a intimidação cotidiana no condomínio fazem ecoar o passado da violência da guerra em seu país de origem - o que faz com que Yaline entre em pânico. As realidades de partida e destino, uma vez aproximadas, se confundem. Os países ricos também se assemelham em sua barbárie.

Ainda sobre a questão da realidade dos imigrantes e, em especial, o fluxo humano de pessoas proveniente de países pobres para os países ricos - algo cada vez mais frequente na mídia internacional -, permite indagar que tipos de significados tais representações evocam. Assim, é possível questionar: seria uma revalorização das imagens de desenvolvimento dos países industrializados da Europa que oculta a deterioração do bem estar social para suas próprias populações; ou ainda, um imperativo normativo de referência, segurança, consumo, portanto, um padrão de nível de vida a ser desejado para os demais povos?

O longa-metragem Deephan se abre para um importante tópico intimamente ligado ao seu tema principal da migração: a importância da cooperação humana fundada na cultura da diferença e no vínculo familiar. O pensamento capitalista neoliberal que orienta os comportamentos, a relação entre os indivíduos para a competitividade e o consumo estimulado pelas mudanças e inovações tecnológicas, não possui o mesmo valor e poder na vida dos personagens. Os protagonistas trazem em sua bagagem uma cultura de tradição milenar, produtora visões de mundo, de identidades, comportamentos e desejos. Segundo Laraya (2013), ainda que a mudança cultural seja posta em curso pela aceleração do contato, neste caso pela emigração forçada, as aprendizagens e adaptações possuem um tempo próprio, revelador do caráter dinâmico da cultura. Mais que um tempo, na visão de BAHABA (2013) este processo não se dá como uma simples troca de ser realizada, ou ainda uma adequação mimética à nova realidade. Ele possui a natureza de um conflito que mobiliza incessantes negociações e disputas.

Tais dimensões se inscrevem no filme, por exemplo, na mudança do padrão de vestimenta dos personagens. $\mathrm{O}$ tênis e o jeans são incorporados, porém o turbante permanece nos espaços públicos. $\mathrm{O}$ mesmo não acontece com o sári e túnica que são confinados ao uso privado, à morada. Esses personagens portadores de uma cultura tradicional não são contrários ao desenvolvimento e as inovações tecnológicas que melhoram o conforto de suas vidas. Eles as incorporam na medida da necessidade, sem abrir mão saberes de saberes tradicionais diversos, competências, e habilidades. Segundo Laraya (2013), tais saberes, se não tratados como científicos, devem ser 


\section{SEMINÁRIO DE PESQUISA EM CIÊNCIAS HUMANAS - SEPECH \\ Humanidades, Estado e desafios didático-científicos \\ Londrina, 27 a 29 de julho de 2016}

entendidos no seio da cultura. Para Cunha (2013), a compreensão deve-se abrir para uma epistême menos colonizadora, mas desenvolvida pelos e a partir do conhecimento daqueles povos tradicionais nos seus processos, nas suas lutas. Deephan conserta os maquinários abandonados, o elevador. Com uma caixa de papelão encontrada no meio de um depósito de objetos descartados e se servindo de materiais e ferramentas rudimentares - tesoura, tecido e cola -, cria um pequeno relicário onde fixa as imagens de seus familiares, possivelmente mortos na guerra.

Neste processo dinâmico do contato cultural, no condomínio, as relações dos personagens com os demais moradores é marcada pela frieza e distância, e o diálogo quase monossilábico. O que não significa uma indiferença e sejam dotadas de certa sedução, como, por exemplo, expressa nos olhares entrecruzados de Yaline na observação do seu jovem patrão, líder de uma das gangues. Tem-ser aí um misto de temor e desejo. Com outros membros de procedência semelhante, portadores de identidades comuns, destituídos de seu território de origem, criam laços de intensa sociabilidade, se reúnem em picnic no parque da cidade, na oração no templo. A vida social entre os semelhantes flui de forma mais amigável e descontraída, sem a ameaça do diferente, constituindo o que na perspectiva Hall (2013) se designa como uma comunidade afetiva na diáspora. A construção do vínculo familiar no filme se desenvolve a partir dos pequenos cuidados; da proteção ante ao ambiente hostil, da solidariedade e do respeito. A inexistência da consanguinidade entre os personagens que se vinculam através do afeto, e ainda que ressurjam os papéis de pai (Deephan), mãe (Yaline) e filha (Ylayall), apontam outras possibilidades de concepção de família. Na visão de Vega (LANGE; MOKRANI, 2011), ainda que a construção social de cooperação se funda na heteronormatividade, o sentido plural da família apresentado pelo filme pode favorecer o estabelecimento de relações de maior igualdade entre as pessoas, contribuindo para uma necessária despatriarcalização da sociedade - qualidade esta imperativa para se alcançar um desenvolvimento mais humano. Neste momento, Deephan e Yaline, que já desempenham os papéis de pai e mãe da pequena Yalayall, avançam na internalização desta função. Contrariando as prescrições de suas culturas no que diz respeito ao sexo antes do casamento, eles se rendem ao desejo da carne com consentimento mútuo e carinho - um comportamento inesperado de um homem proveniente de uma sociedade machista, e militarizada.

O passado belicoso e traumático é evocado nos constantes e crescentes tiros e brigas entre as gangues do condomínio. Uma ameaça a aparente estabilidade da nova família. Em uma atitude desesperada, Deephan traça no pátio da porta de entrada de seu prédio uma linha branca, delimitando uma fronteira - como se fosse possível criar uma zona de segurança neste espaço, e ainda, se sua prática e experiência de combate tivesse ficado para trás. Diante da impossibilidade da paz no condomínio, Deephan trucida todos os membros de uma gangue.

A partir das aproximações propostas entre $\mathrm{o}$ filme $\mathrm{e}$ as teorias de desenvolvimento e cooperação em uma perspectiva epistemológica do Sul, é possível pensar que o trato da migração contemporânea apenas pelos números dos mortos ou sobreviventes que se lançam em direção do continente europeu, não seria uma visão redutora de sua complexidade? Segundo dados da OIM, apenas 1/3 (um terço) dos imigrantes buscam os países desenvolvidos. Somente a Turquia acolheu 02 (dois) milhões em um mesmo ano - o dobro de toda Europa. Neste sentido, questiona-se também: problematizar o fenômeno em tal perspectiva não ocultaria certo temor 


\section{SEMINÁRIO DE PESQUISA EM CIÊNCIAS HUMANAS - SEPECH \\ Humanidades, Estado e desafios didático-científicos \\ Londrina, 27 a 29 de julho de 2016}

ancestral da "riqueza" ante a presença corpórea da "pobreza", no compartilhamento do território, no encontro de culturas diferentes? O que justificaria a interdição das fronteiras gestadas nas desigualdades históricas produzidas pelo sistema econômico vigente? Assim, é possível perceber que a não problematização das motivações históricas-sociais do desenvolvimento e da cooperação, ou mesmo a subjetividade humana na busca da felicidade - o paraíso - como o tratamento do fenômeno também requer, pouco se pode contribui para mitigar esta tragédia denominada de crise humanitária!

Em seu final, o longa-metragem Deephan, através do já mencionado recurso da elipse, suscita uma informação de sentido e significados abertos. Após liquidar a gang do condomínio, Deephan e sua família vivem em outra realidade e em um momento posterior a mencionada chacina na França. Vivem em uma aparente paz e com segurança. Ele trabalha como motorista e mora em um bairro do tipo classe média. Pela posição do volante, à esquerda, se presume que vivem na Inglaterra. Possivelmente foram ao encontro dos parentes de Yaline naquele país. Uma nova criança nasceu para alegria e felicidade do casal. Um lauto churrasco se dá em um jardim ensolarado de sua casa, onde se encontram presentes os novos amigos do lugar: pessoas de diversas procedências e diferentes culturas. Assim, tem-se que o caráter idílico desta imagem paradisíaca, em uma leitura de sua representação ideológica, não poderia ser a afirmação de que a terra prometida, o paraíso redentor deste sofridos imigrantes, seria a Inglaterra - a mãe colônia? Onde a França, dado o esgarçamento do seu tecido social, não mais seria a terra da diferença? Ou se trata de mais um sonho dos imigrantes na busca de representações que permitam um sentido diferente à trágica existência humana?

\section{REFERÊNCIAS}

CRESPO, Antonio Pedro Albernaz; GUROVITZ, Elaine. A pobreza como fenômeno multidimensional. RAE - eletrônica, v. 1, n. 1, jul./dez. 2002. Disponível em: $<$ http://rae.fgv.br/sites/rae.fgv.br/files/artigos/10.1590_S1676-

56482002000200003.pdf>. Acesso em: $1^{\circ}$ fev. 2015.

CUNHA, Manuela Carneiro da. Relações e dissensões entre saberes tradicionais e saberes científicos. In: Cultura com aspas e outros ensaios. 2. ed. São Paulo: Cosac Naify, 2013.

DEEPHAN. Direção: Jacques Audiard. Paris, 2015.

GOSOVIC, Branislav. Global intellectual hegemony and the international development agenda. International Social Science Jounal, v. 52, n. 166, p. 447-456, dez. 2000. Disponível em: <http://onlinelibrary.wiley.com/doi/10.1111/1468-2451.00275/pdf>. Acesso em: $1^{\circ}$ fev. 2015.

GUDINAZ, Eduardo. Sentidos, opciones y ámbitos de las transiciones al postextractivismo. In: LANGE, Miriam; MOKRANI, Dúnia (Orgs.). Más allá Desarrollo. In: I Grupo Permanente de Trabajo sobre Alternativas al Desarrollo, 


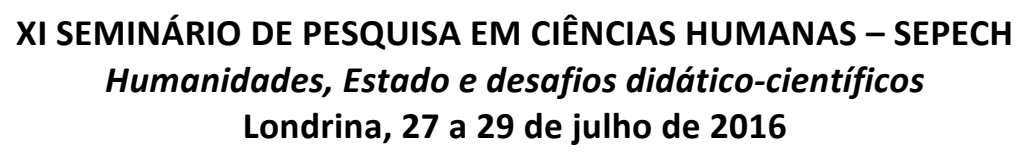

Fundación Rosa Luxemburg/AbyaYala, Quito, p. 295-298, 2011. Disponível em: $<$ http://www.gudynas.com/publicaciones/capitulos/GudynasTransicionesOpcionesFRL Quito11r.pdf>. Acesso em: $1^{\circ}$ fev. 2015.

HALL, Stuart. Da diáspora. Identidades e mediações culturais. Trad. de Adelaine La Guardia Resende. 2. ed. Belo Horizonte: Editora UFMG, 2013.

LARAYA, Roque de Barros. Cultura: um conceito antropológico. 25. ed. Rio de Janeiro: Zahar, 2013.

PINO ,Bruno Ayllón; DOLCETTI, Michele. El buen vivir del Ecuador: crisis del desarrollo y cooperación internacional. Mural Internacional, v. 5, n. 1, p. 28-37, jan./jun. 2014.

RIBEIRO, Gustavo Lins. Poder, redes e ideologia no campo do desenvolvimento. Novos Estudos, CEBRAP, n. 80, p. 109-125, mar. 2008.

TAMBIAH, Stanley J. Conflito etnonacionalista e violência coletiva no Sul da Ásia. Trad. de Vera Pereira. In: Conferências da Associação Nacional de Pesquisa de PósGraduação em Ciências Sociais, São Paulo, 1976. Disponível em: $<$ http://www.ufrgs.br/ppgas/portal/arquivos/orientacoes/TAMBIAH_Stanley_J._1997.p df $>$. Acesso em: 10 maio 2016.

VEGA, Elisa. Descolonizar y despatriarcalizar para vivir bienin. In: LANGE, Miriam; MOKRANI, Dúnia (Orgs.). Más allá Desarrollo. In: I Grupo Permanente de Trabajo sobre Alternativas al Desarrollo, Fundación Rosa Luxemburg/AbyaYala, Quito, p. 295-298, 2011. Disponível em: $<$ http://www.gudynas.com/publicaciones/capitulos/GudynasTransicionesOpcionesFRL Quito11r.pdf>. Acesso em: $1^{\circ}$ fev. 2015. 